\title{
Inhalation Sedation in Subjects With ARDS Undergoing Continuous Lateral Rotational Therapy
}

\author{
Andreas Meiser MD, Heinrich V Groesdonk MD, Sarah Bonnekessel MD, Thomas Volk MD, and \\ Hagen Bomberg MD
}

\begin{abstract}
INTRODUCTION: Isoflurane has shown better sedation control and potential benefits in patients with ARDS compared to propofol or midazolam, but the practical use during continuous lateral rotational therapy remains unknown. We therefore compared isoflurane with propofol and midazolam regarding sedation depth (per the Richmond Agitation-Sedation Scale), opioid consumption, lung function, and hemodynamics in patients treated with continuous lateral rotational therapy. METHODS: 38 consecutive critically ill surgical subjects were retrospectively studied using a hospital database. All subjects suffered from ARDS and were treated with continuous lateral rotational therapy between May 2010 and September 2013. Nineteen subjects were sedated with propofol or midazolam and compared with 19 subjects sedated with isoflurane using the AnaConDa-system. RESULTS: Isoflurane sedation resulted in significantly lower Richmond AgitationSedation Scale scores compared with propofol or midazolam. Despite deep isoflurane sedation, opioid consumption could be significantly reduced. Spontaneous breathing was possible in $90 \%$ of the subjects on isoflurane sedation compared with $16 \%$ of the subjects sedated with propofol or midazolam. The difference between peak inspiratory pressure and PEEP was significantly decreased after $24 \mathrm{~h}$ of isoflurane sedation. Oxygenation $\left(\mathrm{P}_{\mathrm{aO}_{2}} / \mathrm{F}_{\mathrm{IO}}\right)$ improved in both groups. Hemodynamics and need for vasopressor therapy were comparable between groups. CONCLUSIONS: This study supports the feasibility of isoflurane sedation using continuous lateral rotational therapy. Key words: isoflurane; sedation; intensive care unit; Anaconda; Rotorest; acute respiratory distress syndrome; continuous lateral rotational therapy. [Respir Care 2018;63(4):441-447. () 2018 Daedalus Enterprises]
\end{abstract}

\section{Introduction}

Patients suffering from ARDS require invasive positivepressure ventilation as well as some kind of positioning therapy. The S2e German guideline recommends semi-

\footnotetext{
All authors are affiliated with the Department of Anesthesiology, Intensive Care Medicine and Pain Medicine, Saarland University Medical Center, Homburg/Saar, Germany.
}

Dr Meiser discloses relationships with Sedana Medical and Pall Medical. The other authors have disclosed no conflicts of interest.

Correspondence: Hagen Bomberg MD, Department of Anesthesiology, Intensive Care Medicine and Pain Medicine, University Medical Center, University of Saarland, Kirrbergerstrasse 1, 66421 Homburg/Saar, Germany. E-mail: hagen.bomberg@uks.eu.

DOI: $10.4187 /$ respcare.05751 recumbent positioning for all ventilated patients, and prone positioning for those with severe oxygenation failure $\left(\mathrm{P}_{\mathrm{aO}_{2}} / \mathrm{F}_{\mathrm{IO}_{2}}\right.$ below $\left.150 \mathrm{~mm} \mathrm{Hg}\right) .{ }^{1}$ If prone positioning seems contraindicated, as is often the case in patients with multiple trauma or after abdominal surgery with open abdomen or increased intra-abdominal pressure, continuous lateral rotational therapy is recommended as an alternative. Recent data also point to possible advantages of the early use of continuous lateral rotational therapy in patients with cardiogenic shock requiring prolonged ventilator therapy ${ }^{2}$ or those with severe chest trauma to reduce pulmonary complications. ${ }^{3}$

Continuous lateral rotational therapy to maximal angles in awake patients represents a frightening experience and may cause motion sickness and vomiting. Therefore, deep sedation is often used. Current German and Spanish sedation guidelines recommend sedation using an inhaled anesthetic such as isoflurane as an alternative to intravenous sedation, 
especially when deep sedation is indicated. ${ }^{4,5}$ In addition, isoflurane has bronchodilatory effects ${ }^{6,7}$ and lung-protective properties, ${ }^{8}$ which may be of benefit in patients with ARDS undergoing continuous lateral rotational therapy. ${ }^{9}$

The AnaConDa system (Sedana Medical, Uppsala, Sweden), commercially available in Europe and Canada, can be used to deliver inhaled anesthetics via common intensive care ventilators. The device is connected between the $y$-piece of the breathing circuit and the endotracheal tube. Liquid isoflurane is continuously infused by a syringe pump into the device, where it evaporates on the surface of a porous evaporator rod; $90 \%$ of exhaled isoflurane is retained by an anesthetic reflector and resupplied to the patient during the next inspiration. ${ }^{10-12}$

The use of isoflurane sedation in ARDS patients treated with continuous lateral rotational therapy is relatively novel and raises several safety questions. Given that isoflurane is administered via inhalation, the pharmacokinetics are uncertain when given in patients with ARDS who have poor lung function. In addition, the influence on pulmonary function, hemodynamics, and opioid consumption in patients with ARDS who require continuous lateral rotational therapy is unknown. Therefore, we report our experience with a consecutive cohort of 19 subjects with ARDS undergoing continuous lateral rotational therapy with isoflurane sedation. Moreover, we compared these subjects with 19 subjects sedated via the intravenous route using propofol or midazolam, focusing on the Richmond Agitation-Sedation Scale (RASS) score, opioid consumption, lung function, hemodynamics, and outcome. We hypothesized that, despite deep sedation, patients sedated with isoflurane would more often breathe spontaneously.

\section{Methods}

This retrospective case analysis was approved by the local ethics committee (Saarland Medical Chamber, Saarbruecken, Germany). From the hospital information system (SAP Healthcare, Walldorf, Germany), all patients with continuous lateral rotational therapy were identified retrospectively. This cohort of consecutive subjects was treated between May 2010 and September 2013 in the surgical ICU at the Saarland University Medical Center in Homburg, Germany.

The indication to use continuous lateral rotational therapy was severe oxygenation failure $\left(\mathrm{P}_{\mathrm{aO}_{2}} / \mathrm{F}_{\mathrm{IO}_{2}}<150 \mathrm{~mm} \mathrm{Hg}\right)$ with contra-indications for prone positioning. These included use of external fixators at the pelvis or several extremities, or severely distended, open abdomen with negative pressure wound therapy. In some subjects with severe chest trauma, continuous lateral rotational therapy was used early to reduce pulmonary complications. The clinical decision to discontinue continuous lateral rotational therapy was made during

\section{QUICK LOOK}

\section{Current knowledge}

The AnaConDa system can be used to administer volatile anesthetics to critically ill patients using common ICU ventilators. Inhaled sedation with isoflurane is increasingly used by some ICUs in Europe and Canada as an alternative to intravenous sedation with propofol or midazolam, especially when deep sedation is indicated. Possible advantages include better control of sedation depth, shorter awakening times, and the possibility to reduce opioid use.

\section{What this study adds to our knowledge}

This paper describes the safe use of isoflurane in subjects with severe ARDS undergoing continuous lateral rotational therapy. Spontaneous breathing was facilitated despite deep sedation. In this small retrospective study, there were no significant differences in hemodynamics or outcome compared to intravenous sedation.

daily pauses of $60 \mathrm{~min}$, looking at oxygenation and stabilization of pulmonary function.

For continuous lateral rotational therapy we used a special bed that rotated on its long axis (Rotorest, ArjoHuntleigh, Malmö, Sweden). The subject's head, torso, and extremities were supported on all sides with adjustable padded attachments and secured with belts according to the instructions of the manufacturer. The bed turns as much as 62 degrees to both sides. We used full-angle rotation without stopping on any side. Once daily, continuous lateral rotational therapy was paused with the patient in a recumbent position to allow physical examination, chest radiographs, and nursing care.

\section{Group Protocols}

The treatment of all subjects depended on the disease process and not on the mode of sedation. Isoflurane sedation has been available since June 2011. Before that date, all patients received propofol or midazolam for sedation. Since June 2011, the decision to use isoflurane for sedation depended primarily on the availability of the equipment: only one patient could be sedated with AnaConDa at a time.

\section{Artificial Ventilation}

All subjects were ventilated with an Evita 4 ventilator (Dräger Medical, Lübeck, Germany) in pressure-controlled mode (biphasic positive airway pressure). The inspiratory pressure was adjusted to keep the tidal volumes at 
6-8 $\mathrm{mL} / \mathrm{kg}$ ideal body weight. Whenever spontaneous breathing activity was noted, the pressure support mode was used. We used closed endotracheal suctioning in all subjects (Optiflo, Dahlhausen Medizintechnik, Köln, Germany). For subjects sedated with isoflurane, the gas outlet of the ventilator was connected to a FlurAbsorb anesthetic gas filter (Sedana Medical).

\section{Isoflurane Group}

The AnaConDa system and the Vamos gas monitor (Dräger Medical) were set up as prescribed by the manufacturer. Liquid isoflurane was delivered by a syringe pump (Perfusor, Braun Melsungen, Germany). After priming the system, isoflurane was started at a rate of $5 \mathrm{~mL} / \mathrm{h}$ and adjusted according to the clinical condition (hemodynamic stability, RASS scores -4 to -5 ) and the end-tidal anesthetic concentration, which was continuously monitored. The infusion rate needed to keep the subject sedated also depends on the minute ventilation, which may change with time, ${ }^{10}$ the nurses titrated the infusion rate. If rates $>8 \mathrm{~mL} / \mathrm{h}$ were needed, a physician was informed. When starting inhalation sedation, previously used intravenous sedation was stopped without overlap.

In 10 subjects, isoflurane sedation was started immediately, in 4 subjects it was started within $24 \mathrm{~h}$, and in 5 subjects it was started $>24 \mathrm{~h}$ after initiation of continuous lateral rotational therapy. Data were recorded at the start of isoflurane sedation, as well as at 6 and $24 \mathrm{~h}$ after.

\section{Intravenous Group}

Previously used intravenous sedation with either propofol or midazolam was continued unchanged. For a fair comparison of both groups, the observation times were comparable. Therefore, to compare the same time points with regard to the initiation of continuous lateral rotational therapy, subjects were matched by a study nurse blinded to the data and to the purpose of the study: 10 subjects sedated intravenously were randomly selected and assigned to the 10 subjects in whom isoflurane was started immediately after continuous lateral rotational therapy. The remaining patients were randomly matched, and data from the same time points with regard to the start of continuous lateral rotational therapy were collected.

\section{Data Source and Measurements}

Data were extracted from the ICU patient data management system (Copra, Version 5, Copra System, Berlin, Germany). Subject' characteristics, Simplified Acute Physiology II (SAPS II) scores, comorbidities, diagnostic data, drug doses, RASS scores, and details on continuous lateral rotational therapy were entered manually into this system
Table 1. Subjects' Medical History

\begin{tabular}{lccc}
\hline \hline & Propofol/Midazolam & Isoflurane & $P$ \\
\hline Male & $12(63)$ & $14(74)$ & .50 \\
Age, y & $56.3 \pm 21.4$ & $48.9 \pm 16.9$ & .23 \\
Body mass index, $\mathrm{kg} / \mathrm{m}^{2}$ & $25.0 \pm 4.7$ & $28.3 \pm 5.7$ & .062 \\
Comorbidity & & & \\
$\quad$ Coronary heart disease & $1(5)$ & $1(5)$ & $>.99$ \\
$\quad$ Stroke & 0 & $1(5)$ & .31 \\
$\quad$ Renal failure & $1(5)$ & $4(21)$ & .15 \\
COPD & $2(11)$ & $3(16)$ & .63 \\
$\quad$ Diabetes & $2(11)$ & $1(5)$ & .55 \\
Surgery & $9(47)$ & $14(74)$ & .10 \\
$\quad$ Emergency & $15(79)$ & $10(53)$ & .09 \\
Abdominal surgery & $4(21)$ & $6(32)$ & .46 \\
$\quad$ Bone surgery & & & \\
Before Rotorest & $4(21)$ & $7(37)$ & .28 \\
$\quad$ Multiple trauma & $17(90)$ & $17(90)$ & $>.99$ \\
$\quad$ Pneumonia or sepsis & $11(58)$ & $11(58)$ & $>.99$ \\
$\quad$ from other causes & & & \\
Renal replacement therapy & & & \\
\hline$n=19$ for both groups. Data are mean \pm SD or $n(\%)$. & & \\
\hline
\end{tabular}

by physicians and nurses. Vital parameters such as heart rate, invasive mean arterial pressure, blood gases, and ventilatory parameters were automatically transferred to this system and stored after having been checked by the nurses for plausibility.

\section{Data Analysis}

Continuous variables are expressed as mean and SD; categorical variables are presented as absolute and relative frequencies, respectively. Categorical variables in the isoflurane group and the intravenous group were compared using chi-square tests. Continuous variables were compared using Student $t$ tests (or Welch $t$ tests when variance was inhomogeneous). Data analysis was performed using SPSS Statistics 19 (IBM, Ehningen, Germany). Statistical significance was accepted at a 2 -sided significance level of $\alpha=0.05$. Figures were made with GraphPad Prism 5.0 (GraphPad Software, San Diego, California).

\section{Results}

During the observation period, a total of 38 subjects were treated with continuous lateral rotational therapy and sedation. All subjects were studied and followed for hospital stay: 19 in the intravenous and 19 in the isoflurane group.

Subjects' medical histories prior to continuous lateral rotational therapy were not significantly different between groups (Table 1). Causes of ARDS were pneumonia and 


\section{ISOFluRANE AND CONTINUOUS LATERAL RotATIONAL THERAPY}

sepsis from other sources of infection after surgical procedures or multiple trauma. The SAPS II scores were $43.4 \pm 14.8$ in the intravenous and $40.2 \pm 9.6$ in the isoflurane group $(P=.44)$ at initiation of continuous lateral rotational therapy (Table 2). Reasons for continuous lateral rotational therapy were severe oxygenation failure or severe chest trauma. In all subjects, continuous lateral rotational therapy was started within $24-48 \mathrm{~h}$ of meeting clinical criteria. Heart failure was excluded using transesophageal or thoracic echocardiography.

\section{Sedation}

Both groups were deeply sedated after initiation of continuous lateral rotational therapy. Muscular paralysis was not used during the observation period. After isoflurane sedation was started, deep sedation (RASS -4 to -5 ) was readily achievable and RASS was significantly lower after $24 \mathrm{~h}$ compared with the intravenous group (Fig. 1). Despite low RASS Scores, all subjects in both groups showed reactions (coughing) to endotracheal suctioning. The dose of isoflurane was $3-10 \mathrm{~mL} / \mathrm{h}$ with end-tidal concentrations ranging from 0.5 to $0.8 \mathrm{~mL} / \mathrm{dL}$. No technical problems during isoflurane sedation were encountered. During the observation period, slightly more dose changes were performed in the isoflurane group than in the intravenous group $(2.7 \pm 1.9$ vs $1.9 \pm 1.8$, not significant). Opioid consumption was significantly decreased in patients with isoflurane after 6 and $24 \mathrm{~h}$ (Fig. 1, Table 2).

\section{Lung Function}

Interestingly, after $24 \mathrm{~h}$ of isoflurane sedation, $90 \%$ of the subjects were able to breathe spontaneously during deep sedation, compared to only $15 \%$ in the intravenous group (Table 2). In addition, in isoflurane-sedated subjects, $\Delta \mathrm{P}$ (peak inspiratory pressure - PEEP) could be significantly reduced compared to propofol/midazolam, whereas tidal volumes remained unchanged (Fig. 1). The $\mathrm{P}_{\mathrm{aO}_{2}} / \mathrm{F}_{\mathrm{IO}_{2}}$ ratio improved significantly in both groups over time (Table 2).

\section{Hemodynamics}

Inhalation sedation was not associated with hemodynamic instability (Fig. 2). The norepinephrine dose, mean arterial pressure, and heart rate were comparable between the groups. During $24 \mathrm{~h}$ of isoflurane sedation, no significant changes were observed.

\section{Outcome}

There were no significant differences in time on the ventilator, length of stay, or mortality (Table 3 ).
Table 2. SAPS II Score, Sedative Drugs, and Ventilator Parameters Before and During Study Sedation

\begin{tabular}{|c|c|c|c|}
\hline & $\begin{array}{c}\text { Propofol/Midazolam } \\
\quad n=19\end{array}$ & $\begin{array}{l}\text { Isoflurane } \\
n=19\end{array}$ & $P$ \\
\hline \multicolumn{4}{|l|}{ SAPS II, points } \\
\hline Before & $43.2 \pm 15.2$ & $40.2 \pm 9.6$ & .47 \\
\hline $6 \mathrm{~h}$ & $41.4 \pm 14.9$ & $39.2 \pm 9.8$ & .61 \\
\hline $24 \mathrm{~h}$ & $42.6 \pm 13.8$ & $35.7 \pm 10.2$ & .10 \\
\hline Propofol, mg/kg/h & $\mathrm{n}=15$ & $\mathrm{n}=16$ & \\
\hline Before & $0.83 \pm 0.39$ & $0.80 \pm 0.43$ & .83 \\
\hline $6 \mathrm{~h}$ & $0.87 \pm 0.42$ & $0 \pm 0$ & ND \\
\hline $24 \mathrm{~h}$ & $0.10 \pm 0.46$ & $0 \pm 0$ & ND \\
\hline Midazolam, mg/kg/h & $n=4$ & $n=3$ & \\
\hline Before & $0.07 \pm 0.03$ & $0.11 \pm 0.02$ & .060 \\
\hline $6 \mathrm{~h}$ & $0.07 \pm 0.03$ & $0 \pm 0$ & ND \\
\hline $24 \mathrm{~h}$ & $0.10 \pm 0.05$ & $0 \pm 0$ & ND \\
\hline \multicolumn{4}{|l|}{ Isoflurane, $\mathrm{mL} / \mathrm{h}$} \\
\hline Before & $0 \pm 0$ & $0 \pm 0$ & ND \\
\hline $6 \mathrm{~h}$ & $0 \pm 0$ & $5.2 \pm 2.1$ & $\mathrm{ND}$ \\
\hline $24 \mathrm{~h}$ & $0 \pm 0$ & $4.9 \pm 1.7$ & ND \\
\hline Remifentanil, $\mu \mathrm{g} / \mathrm{kg} / \mathrm{min}$ & $\mathrm{n}=14$ & $\mathrm{n}=16$ & \\
\hline Before & $0.22 \pm 0.09$ & $0.19 \pm 0.10$ & .39 \\
\hline $6 \mathrm{~h}$ & $0.23 \pm 0.10$ & $0.10 \pm 0.04 *$ & .007 \\
\hline $24 \mathrm{~h}$ & $0.25 \pm 0.09$ & $0.09 \pm 0.04 *$ & $<.001$ \\
\hline Sufentanil, $\mu \mathrm{g} / \mathrm{kg} / \mathrm{h}$ & $n=5$ & $n=3$ & \\
\hline Before & $0.68 \pm 0.59$ & $0.46 \pm 0.66$ & .64 \\
\hline $6 \mathrm{~h}$ & $0.68 \pm 0.58$ & $0.29 \pm 0.45$ & .20 \\
\hline $24 \mathrm{~h}$ & $0.52 \pm 0.55$ & $0.29 \pm 0.45$ & .38 \\
\hline \multicolumn{4}{|l|}{ Spontaneous breathing } \\
\hline Before & $3(16)$ & $2(11)$ & .64 \\
\hline $6 \mathrm{~h}$ & $3(16)$ & $12(63)$ & .003 \\
\hline $24 \mathrm{~h}$ & $3(16)$ & $17(90)$ & $<.001$ \\
\hline \multicolumn{4}{|l|}{ PEEP, $\mathrm{cm} \mathrm{H}_{2} \mathrm{O}$} \\
\hline Before & $13.5 \pm 2.7$ & $12.2 \pm 2.8$ & .16 \\
\hline $6 \mathrm{~h}$ & $12.7 \pm 3.2$ & $13.9 \pm 3.2$ & .26 \\
\hline $24 \mathrm{~h}$ & $12.7 \pm 3.1$ & $13.2 \pm 3.1$ & .59 \\
\hline \multicolumn{4}{|c|}{ Breathing frequency, breaths/min } \\
\hline Before & $24.6 \pm 5.9$ & $20.2 \pm 5.4$ & .03 \\
\hline $6 \mathrm{~h}$ & $23.5 \pm 5.7$ & $22.4 \pm 5.8$ & .56 \\
\hline $24 \mathrm{~h}$ & $24.7 \pm 5.4$ & $22.0 \pm 6.6$ & .20 \\
\hline \multicolumn{4}{|l|}{ Tidal volume, $\mathrm{mL}$} \\
\hline Before & $499 \pm 134$ & $580 \pm 175$ & .12 \\
\hline $6 \mathrm{~h}$ & $525 \pm 119$ & $606 \pm 204$ & .17 \\
\hline $24 \mathrm{~h}$ & $566 \pm 140$ & $531 \pm 167$ & .50 \\
\hline \multicolumn{4}{|l|}{ Minute volume, $\mathrm{L}$} \\
\hline Before & $12.4 \pm 4.5$ & $11.6 \pm 4.4$ & .61 \\
\hline $6 \mathrm{~h}$ & $12.8 \pm 4.7$ & $13.6 \pm 5.7$ & .52 \\
\hline $24 \mathrm{~h}$ & $13.5 \pm 4.2$ & $11.6 \pm 4.8$ & .22 \\
\hline \multicolumn{4}{|l|}{$\mathrm{P}_{\mathrm{aO}_{2}} / \mathrm{F}_{\mathrm{IO}_{2}}, \mathrm{~mm} \mathrm{Hg}$} \\
\hline Before & $172 \pm 63$ & $157 \pm 71$ & .48 \\
\hline $6 \mathrm{~h}$ & $165 \pm 77$ & $182 \pm 103$ & .58 \\
\hline $24 \mathrm{~h}$ & $199 \pm 73$ & $195 \pm 83$ & .85 \\
\hline \multicolumn{4}{|l|}{$\mathrm{P}_{\mathrm{aCO}_{2}}, \mathrm{~mm} \mathrm{Hg}$} \\
\hline Before & $53 \pm 10$ & $51 \pm 10$ & .52 \\
\hline $6 \mathrm{~h}$ & $53 \pm 10$ & $56 \pm 13$ & .37 \\
\hline $24 \mathrm{~h}$ & $52 \pm 10$ & $58 \pm 14$ & .17 \\
\hline \multicolumn{4}{|c|}{$\begin{array}{l}\text { Data are mean } \pm \mathrm{SD} \text { or } n(\%) \\
\mathrm{ND}=\text { not done } \\
\mathrm{SAPS}=\text { Simplified Acute Physiology Score II } \\
\mathrm{P}_{\mathrm{aCO}_{2}=\text { arterial partial pressure of carbon dioxide }}\end{array}$} \\
\hline
\end{tabular}



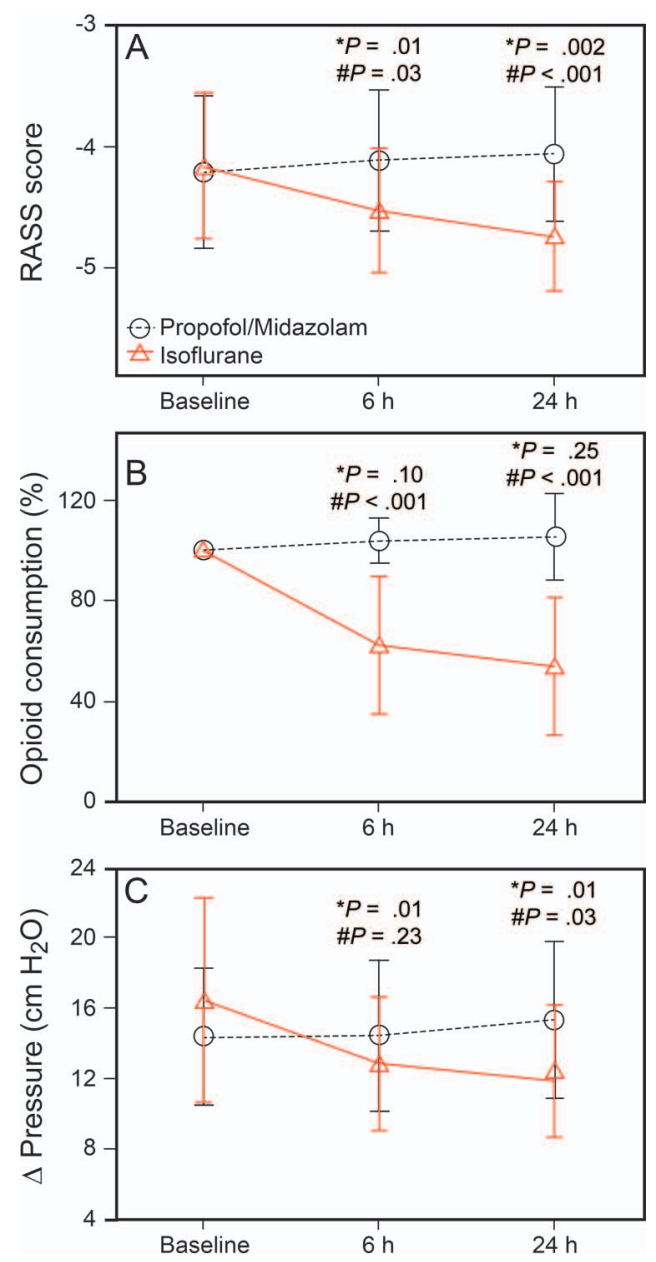

Fig. 1. Richmond Agitation-Sedation Scale (RASS) score (A), opioid consumption $(\mathrm{B})$, and lung function $(\mathrm{C})$; before and during isoflurane sedation compared with propofol/midazolam. Data are shown as mean $\pm \mathrm{SD}$. ${ }^{*} P$ compared to baseline, \# $P$ compared to $\mathrm{propofol} / \mathrm{midazolam}$.

\section{Discussion}

In this study we describe the successful use of isoflurane sedation with the AnaConDa system in 19 subjects being treated with continuous lateral rotational therapy for respiratory failure. This strategy was feasible, with theoretical advantages including bronchodilation, ${ }^{6,7}$ cardiovascular ${ }^{13}$ and lung-protective effects, ${ }^{14,15}$ good control of the level of sedation, ${ }^{16,17}$ and the ability to achieve deep sedation. We compared 19 isoflurane-sedated subjects with 19 subjects sedated via the intravenous route using propofol or midazolam and observed significantly decreased opioid consumption, deeper sedation, more spontaneous breathing, a decreased $\Delta \mathrm{P}$ (peak inspiratory pressure PEEP), and hemodynamically stable conditions after $24 \mathrm{~h}$ isoflurane versus propofol/midazolam.

While receiving isoflurane, all subjects also reacted to endotracheal suctioning despite RASS scores of -4 to -5 .
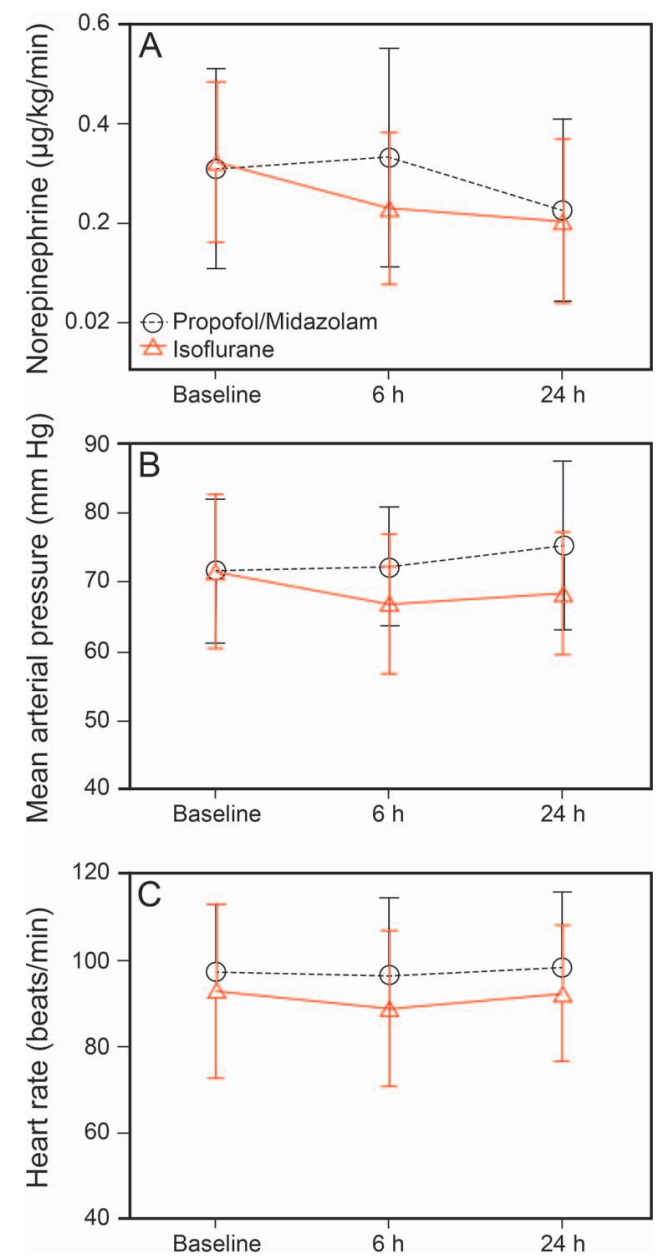

Fig. 2. Norepinephrine dose and hemodynamic data; before and during isoflurane sedation compared with propofol/midazolam. Data are shown as mean \pm SD.

Table 3. Outcomes

\begin{tabular}{lccc}
\hline \hline & $\begin{array}{c}\text { Propofol/ } \\
\text { Midazolam }\end{array}$ & Isoflurane & $P$ \\
\hline Invasive ventilation, h & $618 \pm 503$ & $465 \pm 230$ & .26 \\
Length of stay, d & & & \\
$\quad$ In Rotorest & $6.4 \pm 5.4$ & $7.7 \pm 5.0$ & .44 \\
$\quad$ In ICU & $36 \pm 33$ & $30 \pm 14$ & .48 \\
$\quad$ In hospital & $51 \pm 37$ & $45 \pm 27$ & .60 \\
Mortality during continuous & $4(21)$ & $2(11)$ & .39 \\
$\quad$ lateral rotational therapy & & & \\
& & & \\
\hline$n=19$ for both groups. Data are mean $\pm \mathrm{SD}$ or $n(\%)$. & & \\
\hline
\end{tabular}

Despite deep sedation, opioid administration could be significantly reduced after initiating isoflurane sedation. This observation is in line with previous studies. In the first randomized, controlled trial on inhalation sedation with the AnaConDa system, morphine consumption tended to 
be lower during sedation with isoflurane versus with midazolam ( $2.7 \mathrm{vs} 4.2 \mathrm{mg} / \mathrm{h}$ ). ${ }^{17} \mathrm{In}$ a crossover trial including 17 intensive care subjects, sevoflurane administered without opioid analgesia was equally effective in achieving the sedation targets compared to propofol-remifentanil. ${ }^{18}$ In another randomized, controlled trial, pain scores after stop of sedation as well as morphine consumption $24 \mathrm{~h}$ postextubation were significantly lower after sevoflurane compared to propofol or midazolam sedation. The authors discussed an antihyperalgesic effect of volatile anesthetics. ${ }^{19}$

Interestingly, during deep isoflurane sedation $90 \%$ of the subjects in our study were breathing spontaneously augmented with 5-18 $\mathrm{cm} \mathrm{H}_{2} \mathrm{O}$ pressure support. This was previously described during use of inhalation sedation. ${ }^{18,20,21}$ It can be assumed that augmented spontaneous breathing may recruit lung tissue in dependent areas, which could be of benefit if sufficient PEEP is used to prevent cyclic collapse of alveoli (atalectrauma). ${ }^{22}$

Also of note, $\Delta \mathrm{P}$ was significantly decreased after initiating isoflurane sedation. Possible mechanisms for this effect include purposeful activity of the diaphragm and improved lung compliance due to anti-inflammatory properties of volatile agents. ${ }^{8,23}$ Although some recommend muscular paralysis during the first $48 \mathrm{~h}$ in patients with severe ARDS, ${ }^{24}$ we did not use muscular relaxants because they interfere with monitoring the depth of sedation clinically and preclude spontaneous breathing.

Care must be taken when initiating isoflurane sedation because isoflurane, like propofol, is a potent vasodilator and may cause hemodynamic instability, especially at higher doses. Isoflurane was therefore started at a constant infusion rate, with concentrations building up slowly, and previously used intravenous sedation was stopped without overlap. As most patients in the isoflurane group were previously sedated with propofol, we did not notice a decrease in arterial pressures or an increase in vasopressor use. Also, there was no significant difference in hemodynamics between isoflurane and intravenous sedation.

Because of the high internal dead space of $100 \mathrm{~mL}$ and some $\mathrm{CO}_{2}$ reflection, $\mathrm{CO}_{2}$ removal is impaired with the AnaConDa device. ${ }^{17,20,25}$ We noted a slight increase in $\mathrm{P}_{\mathrm{aCO}_{2}}$, but this was not significant. Consequently, tidal volumes $>350 \mathrm{~mL}$ are normally recommended, which may preclude the use of this device when low-volume lung-protective ventilation strategies are used in smaller patients. In our study, all subjects had tidal volumes $>350 \mathrm{~mL}$ with sufficient elimination of $\mathrm{CO}_{2}$ in both groups. However, a reduction in device dead space of the AnaConDa system would be desirable.

In all study subjects, we used closed endotracheal suctioning to allow removal of respiratory secretions without loss of airway pressure and to reduce workplace contamination with isoflurane. There were no problems with se- cretions in these subjects, although copious secretions may interfere with proper function of the AnaConDa device.

Isoflurane-sedated subjects had significantly lower RASS scores, which suggest deeper sedation. It was shown that deep intravenous sedation is associated with an increase in mortality. ${ }^{26-28}$ However, one previous study suggests that the mortality of long-term ventilated critically ill subjects sedated with isoflurane may be lower than that of patients sedated intravenously with propofol or midazolam. ${ }^{29}$ In line with this, in our study there was no increased mortality in subjects sedated deeply with isoflurane (11\%) compared to subjects sedated with propofol/midazolam at higher RASS scores $(21 \%, P=.37)$. Nevertheless, our study was not powered to detect differences in mortality. Further multi-center, randomized, controlled trials are needed to investigate the possible benefits of sedation with isoflurane in patients with ARDS.

\section{Conclusion}

We found that sedation with isoflurane was successful in critically ill subjects on continuous lateral rotational therapy. Subjects required less opioids and were able to breathe spontaneously while deeply sedated compared to sedation with propofol/midazolam. No adverse events were noted related to isoflurane sedation.

\section{ACKNOWLEDGMENTS}

We thank Karen Schneider for her critical revisions. The presented data are part of the doctoral thesis of Sarah Bonnekessel.

\section{REFERENCES}

1. Bein T, Bischoff M, Brückner U, Gebhardt K, Henzler D, Hermes C, et al. S2e guideline: positioning and early mobilisation in prophylaxis or therapy of pulmonary disorders: revision 2015; S2e guideline of the German Society of Anaesthesiology and Intensive Care Medicine (DGAI). Anaesthesist 2015;64(Suppl 1):1-26.

2. Simonis G, Steiding K, Schaefer K, Rauwolf T, Strasser RH. A prospective, randomized trial of continuous lateral rotation ("kinetic therapy") in patients with cardiogenic shock. Clin Res Cardiol 2012; 101(12):955-962.

3. Wutzler S, Sturm K, Lustenberger T, Wyen H, Zacharowksi K, Marzi I, Bingold T. Kinetic therapy in multiple trauma patients with severe thoracic trauma: a treatment option to reduce ventilator time and improve outcome. Eur J Trauma Emerg Surg 2017;43(2):155161.

4. Baron R, Binder A, Biniek R, Braune S, Buerkle H, Dall P, et al. Evidence and consensus based guideline for the management of delirium, analgesia, and sedation in intensive care medicine. Revision 2015 (DAS-Guideline 2015) - short version. Ger Med Sci 2015; 13:Doc19.

5. Celis-Rodriguez E, Birchenall C, de la Cal MA, Castorena Arellano G, Hernandez A, Ceraso D, et al. Clinical practice guidelines for evidence-based management of sedoanalgesia in critically ill adult patients. Med Intensiva 2013;37(8):519-574. 


\section{ISOFluRANE AND CONTINUOUS LATERAL RotATIONAL THERAPY}

6. Thomson H, Harper NJ, Parkes A. Use of the AnaConDa anaesthetic delivery system to treat life-threatening asthma. Anaesthesia 2007; 62(3):295-296.

7. Maltais F, Sovilj M, Goldberg P, Gottfried SB. Respiratory mechanics in status asthmaticus. Effects of inhalational anesthesia. Chest 1994;106(5):1401-1406.

8. O'Gara B, Talmor D. Lung protective properties of the volatile anesthetics. Intensive care medicine 2016;42(9):1487-1489.

9. Bomberg H, Groesdonk HV, Bellgardt M, Volk T, Meiser A. AnaConDa and Mirus for intensive care sedation, $24 \mathrm{~h}$ desflurane versus isoflurane in one patient. SpringerPlus 2016;5:420.

10. Meiser A, Bellgardt M, Belda J, Rohm K, Laubenthal H, Sirtl C. Technical performance and reflection capacity of the anaesthetic conserving device: a bench study with isoflurane and sevoflurane. J Clin Monit Comput 2009;23(1):11-9.

11. Bomberg H, Wessendorf M, Bellgardt M, Veddeler M, Wagenpfeil $\mathrm{S}$, Volk T, et al. Evaluating the efficiency of desflurane reflection in two commercially available reflectors. J Clin Monit Comput 2016 [Epub ahead of print] doi: 10.1007/s10877-016-9902-0.

12. Meiser A, Bomberg H, Volk T, Groesdonk HV. [New technical developments for inhaled sedation]. Anaesthesist. 2017.

13. Kikuchi C, Dosenovic S, Bienengraeber M. Anaesthetics as cardioprotectants: translatability and mechanism. British journal of pharmacology 2015;172(8):2051-2061.

14. Englert JA, Macias AA, Amador-Munoz D, Pinilla Vera M, Isabelle $\mathrm{C}$, Guan J, et al. Isoflurane ameliorates acute lung injury by preserving epithelial tight junction integrity. Anesthesiology 2015;123(2): 377-388.

15. Voigtsberger S, Lachmann RA, Leutert AC, Schlapfer M, Booy C, Reyes L, et al. Sevoflurane ameliorates gas exchange and attenuates lung damage in experimental lipopolysaccharide-induced lung injury. Anesthesiology 2009;111(6):1238-1248.

16. Kong KL, Willatts SM, Prys-Roberts C. Isoflurane compared with midazolam for sedation in the intensive care unit. BMJ 1989; 298(6683):1277-1280.

17. Sackey PV, Martling CR, Granath F, Radell PJ. Prolonged isoflurane sedation of intensive care unit patients with the Anesthetic Conserving Device. Crit Care Med 2004;32(11):2241-2246.

18. Migliari M, Bellani G, Rona R, Isgro S, Vergnano B, Mauri T, et al. Short-term evaluation of sedation with sevoflurane administered by the anesthetic conserving device in critically ill patients. Intensive Care Med 2009;35(7):1240-1246.

19. Mesnil M, Capdevila X, Bringuier S, Trine PO, Falquet Y, Charbit $\mathrm{J}$, et al. Long-term sedation in intensive care unit: a randomized comparison between inhaled sevoflurane and intravenous propofol or midazolam. Intensive Care Med 2011;37(6):933-941.

20. Chabanne R, Perbet S, Futier E, Ben Said NA, Jaber S, Bazin JE, et al. Impact of the anesthetic conserving device on respiratory parameters and work of breathing in critically ill patients under light sedation with sevoflurane. Anesthesiology 2014;121(4):808-816.

21. Meiser A, Laubenthal H. Inhalational anaesthetics in the ICU: theory and practice of inhalational sedation in the ICU, economics, riskbenefit. Best Pract Res Clin Anaesthesiol 2005;19(3):523-538.

22. Guldner A, Braune A, Carvalho N, Beda A, Zeidler S, Wiedemann $\mathrm{B}$, et al. Higher levels of spontaneous breathing induce lung recruitment and reduce global stress/strain in experimental lung injury. Anesthesiology 2014;120(3):673-682.

23. Jabaudon M, Boucher P, Imhoff E, Chabanne R, Faure JS, Roszyk L, et al. Sevoflurane for sedation in ARDS: a randomized controlled pilot study. Am J Resp Crit Care Med 2016;195(6):792-800.

24. Papazian L, Forel JM, Gacouin A, Penot-Ragon C, Perrin G, Loundou A, et al. Neuromuscular blockers in early acute respiratory distress syndrome. New Engl J Med 2010;363(12):1107-1116.

25. Sturesson LW, Bodelsson M, Jonson B, Malmkvist G. Anaesthetic conserving device AnaConDa: dead space effect and significance for lung protective ventilation. Br J Anaesth 2014;113(3):508-514.

26. Brook AD, Ahrens TS, Schaiff R, Prentice D, Sherman G, Shannon W, Kollef MH. Effect of a nursing-implemented sedation protocol on the duration of mechanical ventilation. Crit Care Med 1999; 27(12):2609-2615.

27. Kress JP, Pohlman AS, O'Connor MF, Hall JB. Daily interruption of sedative infusions in critically ill patients undergoing mechanical ventilation. New Engl J Med 2000;342(20):1471-1477.

28. Shehabi Y, Chan L, Kadiman S, Alias A, Ismail WN, Tan MA, et al. Sedation depth and long-term mortality in mechanically ventilated critically ill adults: a prospective longitudinal multicentre cohort study. Intensive Care Med 2013;39(5):910-918.

29. Bellgardt M, Bomberg H, Herzog-Niescery J, Dasch B, Vogelsang $\mathrm{H}$, Weber TP, et al. Survival after long-term isoflurane sedation as opposed to intravenous sedation in critically ill surgical patients: retrospective analysis. Eur J Anaesthesiol 2016;33(1):6-13. 